\title{
A Role for Tectal Midline Glia in the Unilateral Containment of Retinocollicular Axons
}

\author{
Da-Yu Wu, ${ }^{1}$ Gerald E. Schneider, ${ }^{1}$ Jerry Silver, ${ }^{2}$ Michael Poston, ${ }^{2}$ and Sonal Jhaveri ${ }^{1}$ \\ 1Department of Brain and Cognitive Sciences, Massachusetts Institute of Technology, Cambridge, Massachusetts 02139, \\ and ${ }^{2}$ Department of Neuroscience, Case Western Reserve Medical School, Cleveland, Ohio 44106
}

Retinal fibers approach close to the tectal midline but do not encroach on the other side. Just before the entry of retinal axons into the superior colliculus (SC), a group of radial glia differentiates at the tectal midline; the spatiotemporal deployment of these cells points to their involvement in the unilateral containment of retinotectal axons.

To test for such a barrier function of the tectal midline cells, we used two lesion paradigms for disrupting their radial processes in the neonatal hamster: (1) a heat lesion was used to destroy the superficial layers of the right SC, including the midline region, and (2) a horizontally oriented hooked wire was inserted from the lateral edge of the left SC toward the midline and was used to undercut the midline cells, leaving intact the retinorecipient layers in the right SC. In both cases, the left SC was denervated by removing its contralateral retinal input. Animals were killed $12 \mathrm{hr}$ to 2 weeks later, after intraocular injections of anterograde tracers to label the axons from the remaining eye. Both lesions resulted in degeneration of the distal processes of the tectal raphe glia and in an abnormal crossing of the tectal midline by retinal axons, leading to an innervation of the opposite ("wrong") tectum. The crossover occurred only where glial cell attachments were disrupted.

These results document that during normal development, the integrity of the midline septum is critical in compartmentalizing retinal axons and in retaining the laterality of the retinotectal projection.

Key words: midline septum; GFAP; axon barrier; radial glia; axon guidance; brain compartmentalization
Glial cells have supportive or attractive influences on axon growth (Singer et al., 1979; Whitehead and Morest, 1981; Silver and Rutishauser, 1984; Dodd and Jessell, 1988; Muller and Best, 1989; Vanselow et al., 1989; Aguayo et al., 1990; Hatten, 1990; Abbott, 1991; Schachner, 1991) and play an inhibitory or repulsive role during fiber extension (Patterson, 1988; Chiquet, 1989; Joosten and Gribnau, 1989; Steindler et al., 1989, 1990; Snow et al., 1990a; Schwab and Schnell, 1991; Schwab et al., 1993; Steindler, 1993). We focus here on the latter function, particularly on the compartmentalization of growing fiber systems by glia.

Glycoproteins expressed on oligodendrocytes inhibit axon growth. Antibodies that neutralize this inhibition allow for fiber regrowth (Schwab and Schnell, 1991; Kapfhammer et al., 1992; Schwab et al., 1993), suggesting that differentiating oligodendroglia outline spatial domains that contain late-developing fiber systems (Schwab, 1990; Kapfhammer and Schwab, 1994; Schwegler et al., 1995). Glial cell-associated glycoconjugates form boundaries that delineate compartments in the developing brain (Steindler and Cooper, 1987; Steindler et al., 1989, 1990); in the barrelfield cortex, glycoconjugate patterning reflects the organization of whiskers on the snout (Blue et al., 1991; Jhaveri et al., 1991b; Bennett-Clarke et al., 1994; Schlaggar and O’Leary, 1994)

\footnotetext{
Received Dec. 31, 1997; revised July 23, 1998; accepted July 30, 1998.

This work was supported by National Institutes of Health Grants EY00126 (G.E.S.), EY05504 (S.J.), and EY02621 (Vision Core Grant). We thank Chrysty Remillard for help with the photography and Dr. Alan Harvey for discussions on interactions of nonretinal afferents with the tectal midline.

Correspondence should be addressed to Dr. Sonal Jhaveri, Department of Brain and Cognitive Sciences, E25-642, Massachusetts Institute of Technology, Cambridge, MA 02139.

Dr. Wu's present address: University of Southern California School of Medicine, Department of Cell and Neurobiology, Los Angeles, CA 90033

Copyright (C) 1998 Society for Neuroscience $\quad 0270-6474 / 98 / 188344-12 \$ 05.00 / 0$
}

and may serve to maintain the tangential coordinates of clustered thalamocortical fibers (Steindler et al., 1990; Steindler, 1993). It is suggested that upregulation of proteoglycans within the extracellular matrix of reactive astroglia contributes to regenerative failure of adult axons in white matter tracts (Davies et al., 1997). Glia along the spinal roof plate are implicated in blockading dorsal column axons from invading contralaterally, most likely via sulfated proteoglycans (PGs) (Snow et al., 1990a,b; Pindzola et al., 1993). Midline glia along the caudal neuraxis are absent in regions where corticospinal fibers decussate, indicating a role in retaining the laterality of corticospinal axons (Joosten and Gribnau, 1989). Differential interactions of nasal or temporal retinal axons with cells (early neurons and/or radial glia) at the optic chiasm direct the routing of these fibers (Godement et al., 1990; Godement and Mason, 1993; Wizenmann et al., 1993; Sretavan et al., 1995).

A group of radial cells resides along the tectal midline (Jhaveri et al., 1992; Wu et al., 1995). These are distinct from other tectal glia in their timing of differentiation, morphology, and molecular composition. Damage to the midline surface in neonatal rodents results in a bilateral invasion (across the midline) of the tectum by retinal axons from a single eye (Schneider, 1973; Hsiao and Schneider, 1978; Jen and Lund, 1979); no crossing of the tectal midline by retinal axons is detected if the lateral tectum, but not the midline, is damaged (So and Schneider, 1978; Schneider et al., 1985). These results suggest that normally, a structure(s) along the midline compartmentalizes retinotectal axons to one side. Here, we document an involvement of the tectal raphe glia in mediating such a barrier function. We show that retinal axons can be induced to cross the tectal midline abnormally but only where the pial processes of midline glia have been disrupted. 


\section{MATERIALS AND METHODS}

Syrian hamsters (Mesocricetus auratus) were bred in the animal facility at the Massachusetts Institute of Technology, or timed-pregnant females were purchased from Charles River Laboratories (Wilmington, MA). The Massachusetts Institute of Technology Committee on Animal Care approved protocols for all surgical procedures involving live animals.

\section{Surgical procedures}

Unilateral tectal lesions. Postnatal day 1 (P1) hamster pups were anesthetized by hypothermia, the skin overlying the tectum was incised, and the flat head of a pin was heated and applied for a few seconds to the cartilaginous skull overlying the right superior colliculus (SC). The right eye was also removed. The skin was sutured, and the pup was warmed and returned to the home nest.

Undercutting the midline glial cells. Animals were anesthetized by hypothermia on P1, and the skull covering the SC was exposed as described above. A small slit was made with a number 11 scalpel blade at the lateral edge of the skull covering the left SC; a hooked tungsten wire was inserted through the slit and pushed medially, below the pia, all the way to the midline. The wire was then moved in the horizontal plane to disrupt the pial processes of the raphe glia, while the retinorecipient layers of the right tectum were maintained intact. The right eye was also removed at the same time to denervate the left SC. Earlier studies had shown that such denervation induces a larger number of retinal axons from the remaining left eye to cross the tectal midline and to abnormally innervate the left tectum (Schneider, 1973; So and Schneider, 1978). Animals were warmed, returned to the home nest, and killed after varying survival times ( $12 \mathrm{hr}$ to 3 weeks). To control for effects of the eye removal, the midline undercutting surgery was done on a group of newborn animals without enucleating the right eye. To control for the lesion made in the left SC by the tungsten wire, surgery was performed on a group of animals as described above, except that the wire was advanced just short of the midline, and the midline (raphe) glia were not severed; in these cases the right eye was also removed, as for the experimental animals.

\section{Horseradish peroxidase eye injection and retinotectal axon labeling}

Hamsters with unilateral SC lesions were perfused 10-21 d after surgery. Pups (at least five at each time point) with a midline undercut were killed at P12 or P14; two animals were perfused on P7. Control animals were age-matched to the corresponding experimental hamsters at the time of perfusion. One day before being killed, the animal was fully anesthetized with hypothermia (for the neonates) or with Chloropent $(0.35 \mathrm{ml} / 100 \mathrm{gm}$ body weight), and $1-3 \mu$ of $40-50 \%$ horseradish peroxidase (HRP) (type VI; Sigma, St. Louis, MO) made up in $2 \%$ dimethylsulfoxide was injected into the left eye, with use of a micropipette attached to a Drummond Scientific (Broomall, PA) microdispenser or a picospritzer (World Precision Instruments, Sarasota, FL). Animals were killed with an overdose of anesthesia and perfused transcardially with an initial rinse of $0.9 \%$ sodium chloride containing $0.25 \%$ of the vasodilator sodium nitrite. This was followed by $4 \%$ paraformaldehyde made up in $0.1 \mathrm{M}$ phosphate buffer (PB), $\mathrm{pH}$ 7.4. The brains were not post-fixed but were immediately dissected out and stored in PB for $<1$ week. Brains prepared for light microscopy were cryoprotected in $30 \%$ sucrose (made up in $\mathrm{PB}, \mathrm{pH} 7.4$ ) and cut coronally at a thickness of $40-50 \mu \mathrm{m}$ on a cryomicrotome. Three parallel series of sections were collected; one was reacted with tetramethylbenzidine (Sigma) to visualize the HRP-labeled retinal fibers as described previously (Jhaveri et al., 1988). The other two groups of adjacent sections were immunostained (see below). All sections were mounted onto gelatin-coated microscope slides, counterstained with neutral red, air dried, and coverslipped after brief alcohol dehydration and xylene clearing.

\section{Immunohistochemistry}

Sections adjacent to those reacted for HRP were immunostained using monoclonal antibodies against the glial fibrillary acidic protein (GFAP) or against vimentin (both antibodies from Boehringer Mannheim, Indianapolis, IN). All steps were performed under gentle agitation. Sections were rinsed in PBS, and nonspecific binding was blocked by incubation in $20 \%$ normal horse serum (Life Technologies, Grand Island, NY) in PBS. They were next incubated in primary antibody (1:30 dilution) made up in PBS containing $1 \%$ normal horse serum, $0.3 \%$ Triton $\mathrm{X}-100$, and $0.2 \%$ sodium azide, for $18-24 \mathrm{hr}$ at room temperature (or for $96 \mathrm{hr}$ at $4^{\circ} \mathrm{C}$ ).
They were rinsed and then transferred to biotinylated horse anti-mouse IgG (1:200 dilution made up in PBS, horse serum, and Triton X-100; Vector Laboratories, Burlingame, CA) for $1 \mathrm{hr}$ at room temperature. Sections were rinsed again, immersed in an avidin-biotin-HRP complex solution (ABC kit; Vector Laboratories) for $1 \mathrm{hr}$, after which the HRP was visualized using hydrogen peroxide, with diaminobenzidine tetrahydrochloride as a chromagen. Control sections for immunostaining were processed using the same solutions, except that the primary antibody was omitted in the first incubation. Sections were mounted on gelatinized slides, dried overnight, cleared in xylene, and coverslipped.

\section{Quantitation}

The tectal midline was reconstructed in dorsal view from coronal sections through the brains of six animals in which the midline glial processes were undercut. Alternate sections from these brains were stained with GFAP or reacted for visualizing the HRP-labeled retinal axons. Hatched lines (see Fig. 11) represent the distance (arbitrary scale) along the rostrocaudal axis where pial processes of the raphe glia were intact (i.e., not cut by the sweep of the hooked wire). The distance along the rostrocaudal axis over which HRP-labeled retinal fibers could be seen crossing the midline was represented by $X$ s (see Fig. 11). The region of the midline along which the pial processes of glial cells were disrupted, but no HRP-labeled axons were seen crossing to the opposite side, was represented as a thick line (see Fig. 11).

\section{1,1'-Dioctadecyl-3,3,3',3'-tetramethylindocarbocyanine} perchlorate labeling of retinal axons and

\section{4-(4-dihexadecylaminostyryl)-N-methylpyridinium} iodide labeling of midline radial glia

Midline undercutting surgery was performed on P1 pups, as above. On P2 ( $24 \mathrm{hr}$ after surgery), the pups were reanesthetized by hypothermia, and a solution of 1,1'-dioctadecyl-3,3,3',3'-tetramethylindocarbocyanine perchlorate (DiI) (Molecular Probes, Eugene, OR) dissolved in dimethyl formamide was injected into the left eye. Animals were allowed to survive for another 1-2 d, were overdosed with pentobarbital, and perfused with $4 \%$ paraformaldehyde, and 4-(4-dihexadecylaminostyryl)$N$-methylpyridinium iodide (DiA) (Molecular Probes) was placed in the dorsal wall of the ventricle at the level of the cerebral aqueduct of Sylvius. The labeled brain was returned to $4 \%$ paraformaldehyde for $4-15 \mathrm{~d}$ at room temperature. Brains were then cut on a vibratome into $100-\mu \mathrm{m}-$ thick transverse sections, and tissue was collected in $0.1 \mathrm{M} \mathrm{PB}$, mounted onto microscope slides, and coverslipped wet in PBS. The edges of the coverslips were sealed with nail polish. DiI labeling of retinal axons in the tectum was analyzed and photographed with a Nikon epifluorescence microscope using a rhodamine filter. DiA-labeled radial processes on the same section were photographed with use of a fluorescein filter.

\section{Electron microscopy}

Normal hamsters and hamsters that had received a unilateral heat lesion of the SC on $\mathrm{P} 0$ or $\mathrm{P} 1$ survived until $\mathrm{P} 6$, at which point they were perfused with $4 \%$ paraformaldehyde and $3 \%$ glutaraldehyde in PBS. The brains were removed and post-fixed in the same solution. Coronal sections through the midbrain were cut on a vibratome, rinsed in PBS, osmicated (1\% osmium tetroxide in $\mathrm{PB}$ ) for $1-3 \mathrm{hr}$ at room temperature, and rinsed again in buffer. They were sequentially dehydrated in a series of ethyl alcohols and then in a mixture of ethyl alcohol and Spurr's resin and were finally polymerized in fresh Spurr's resin. Semithin sections, stained with toluidine blue, provided orientation to trim the block around the tectal midline. Ultrathin sections were cut on a DuPont (Billerica, MA) MT-5000 ultramicrotome; they were mounted on formvar-coated copper mesh grids, stained with lead citrate and uranyl acetate, and viewed on a Zeiss 109 electron microscope.

\section{RESULTS}

\section{Midline radial glia and retinotectal projections in PO hamsters}

In normal animals, the tectal midline is comprised of tightly bundled radial cells whose perikarya are positioned around the lumen of the ventricle and whose radial processes span the thickness of the colliculus and are embedded in the pial surface. We refer to these radial extensions as the pial processes of the midline glia. Details of the development of these cells have been provided 

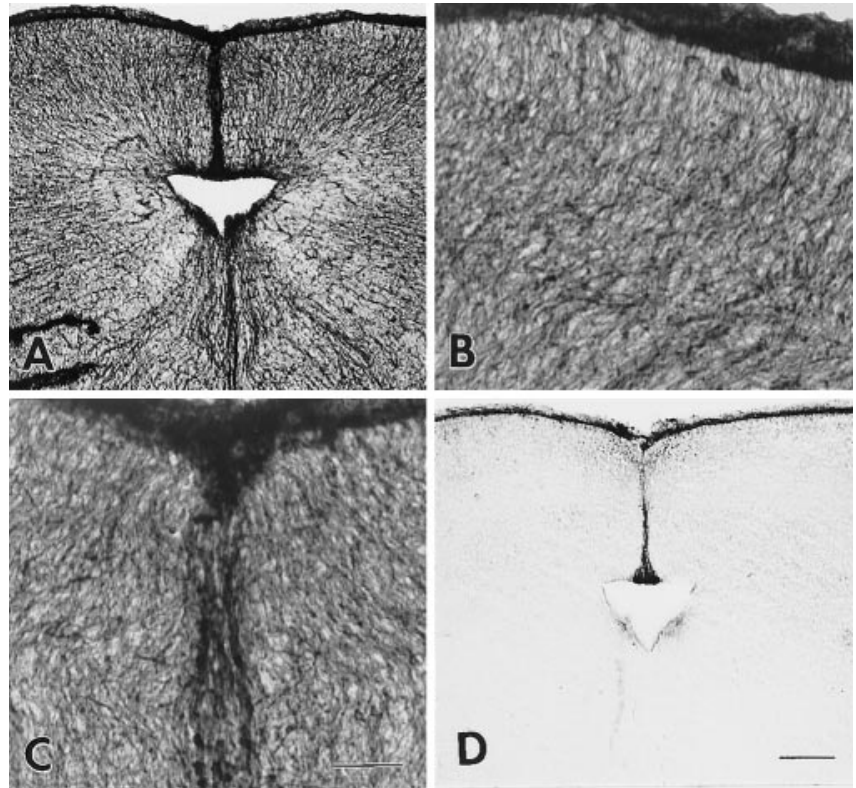

Figure 1. Coronal sections through the SC of a hamster on the day after birth (P1). The tissue was stained with an antibody against vimentin $(A-C)$ or against the GFAP $(D)$. Vimentin-positive radial processes extend between the ventricular surface and the pial surface $(A, B)$. The midline cells $(C)$ are densely bundled and intensely vimentin-reactive, and their pial processes are embedded in the pial surface. Only the midline cells are GFAP-positive in the P1 tectum $(D)$. Scale bar (in $C$ ): $A$, $D, 200 \mu \mathrm{m} ; B, C, 50 \mu \mathrm{m}$.

by $\mathrm{Wu}$ et al. (1995). Here, we briefly review salient light microscope observations that are relevant to the present study.

On $\mathrm{P} 0-\mathrm{P} 1$, vimentin immunoreactivity revealed radial cells in the lateral tectum, as well as along the midline (Fig. $1 A-C$ ); the latter were particularly striking because of their density and the bundling of their processes. These midline cells retained their vimentin expression at least until P12 (Fig. 2A). No lateral radial cells stained positively with the GFAP antibody that we used in this study. On the other hand, the midline cells were intensely reactive for this intermediate filament protein, both in neonates and at least through the second week of postnatal life (Figs. 1D, $2 B$ ) but not in embryonic animals. As has been shown before for all normal rodents, HRP-labeled retinal axons that projected to the superficial gray layer (SGS) of the contralateral tectum were retained within the SC on one side, with no encroachment of the visual axons across the tectal midline (Fig. $2 C, D$ ). (Retinotectal axons that are deflected ipsilaterally at the chiasm normally approach the tectum from the rostral end, as do the ones from the contralateral eye; they do not cross the tectal midline.) The following experiments describe the relationship between the damage inflicted on the midline glia and the altered projection patterns of retinotectal afferents (Jhaveri, 1993a,b; Jhaveri and Hoffman-Kim, 1996).

\section{Disruption of the midline after heat lesions of the tectum}

As a consequence of heat damage at the tectal surface, the underlying tissue became necrotic, and a cyst formed in this region (Fig. 3). Eight days after lesion, HRP-labeled retinal axons could be followed into the region of damage and across the tectal midline into the contralateral SC. These axons took two paths to the opposite side. The first was a membranous bridge, which provided a substrate for the axons to travel over the cyst and into
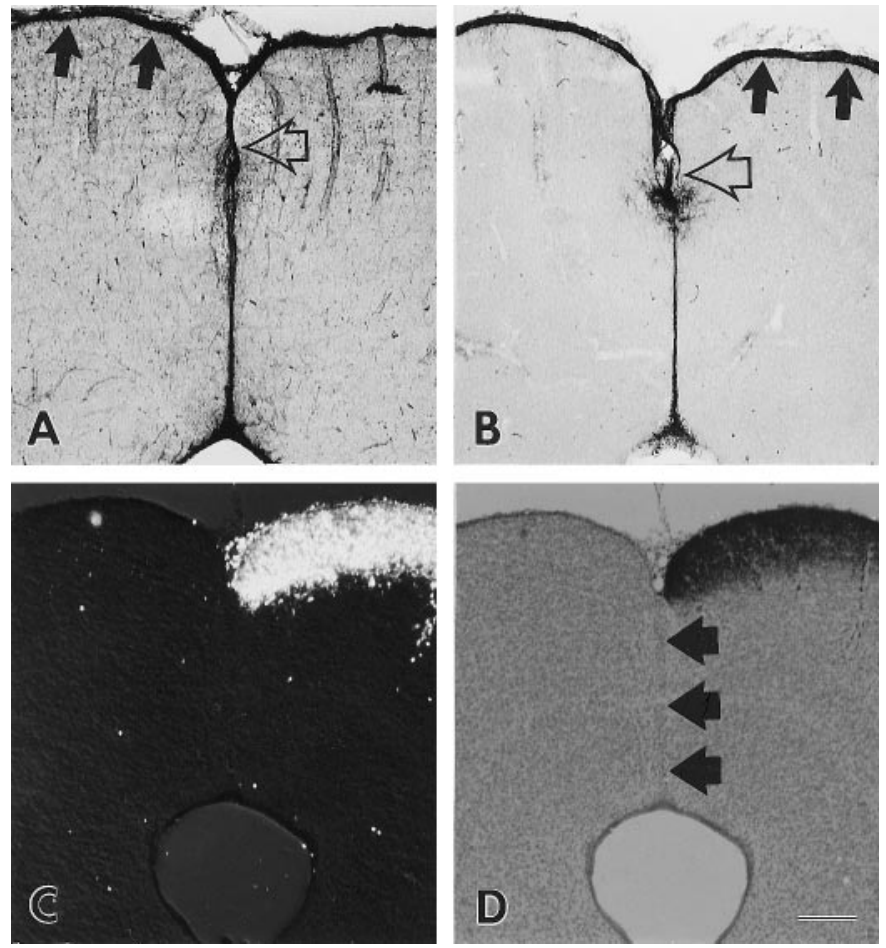

Figure 2. Coronal sections through the SC of a P12 hamster immunostained to visualize vimentin $(A)$ and GFAP expression $(B)$. Note that at this age, the lateral radial cells exhibit little expression of either protein, whereas both vimentin and GFAP can still be detected in the midline cells. Filled arrows point to pia, and open arrows point to pial ends of midline glial cells. $C, D$, Dark-field (polarized light) and light-field images, respectively, of the distribution of the normal retinotectal projection as seen in a coronal section through the midbrain of a P12 animal whose left eye was injected with HRP. The sections were reacted with tetramethylbenzidine and counterstained with neutral red. Arrows in $D$ point to the midline. Radial processes are not specifically stained in this preparation. Scale bar (in $D$ ): $A-D, 200 \mu \mathrm{m}$.

the contralateral SC (Fig. $3 A, B$ ). Immunostaining of sections immediately adjacent to the ones in which HRP-labeled retinal axons had been visualized in this bridge revealed that GFAPpositive processes (of unknown origin) lined this upper membranous route (Fig. 3D). In addition, retinal axons were also seen coursing along the surface of the remnant SC, subjacent to the necrotic tissue (Fig. 3A,B) (So, 1979; Harvey et al., 1986). This second route occurred in the region where the pial processes of the midline raphe cells had been disrupted (Figs. 3, compare $A, B$ and $C, D ; 4)$ : most of the pial attachments of the raphe glia had pulled back from the surface or were degenerating. The neatly bundled GFAP-positive processes, normally attached at the pial surface of the midline, were no longer visible (Fig. 4). However, the glial cell somata, along with their more proximal radial processes, were still tethered at the ventricular surface (Figs. $4 A, B, 5 C$ ). Higher magnification views (Fig. 5) showed that the disruption of the radial processes created a "gap" just below the pial surface (Fig. 5A,C) and that retinal axons were confined to travelling through this gap. Nevertheless, surface view reconstructions of the tectal midline illustrated that the gap in the midline glia was not coextensive with the region over which the axons crossed but that it spanned a larger rostrocaudal extent of the SC than the region within which retinal axon crossover occurred (see Fig. 11, quantitation for the midline undercut cases presented below). 


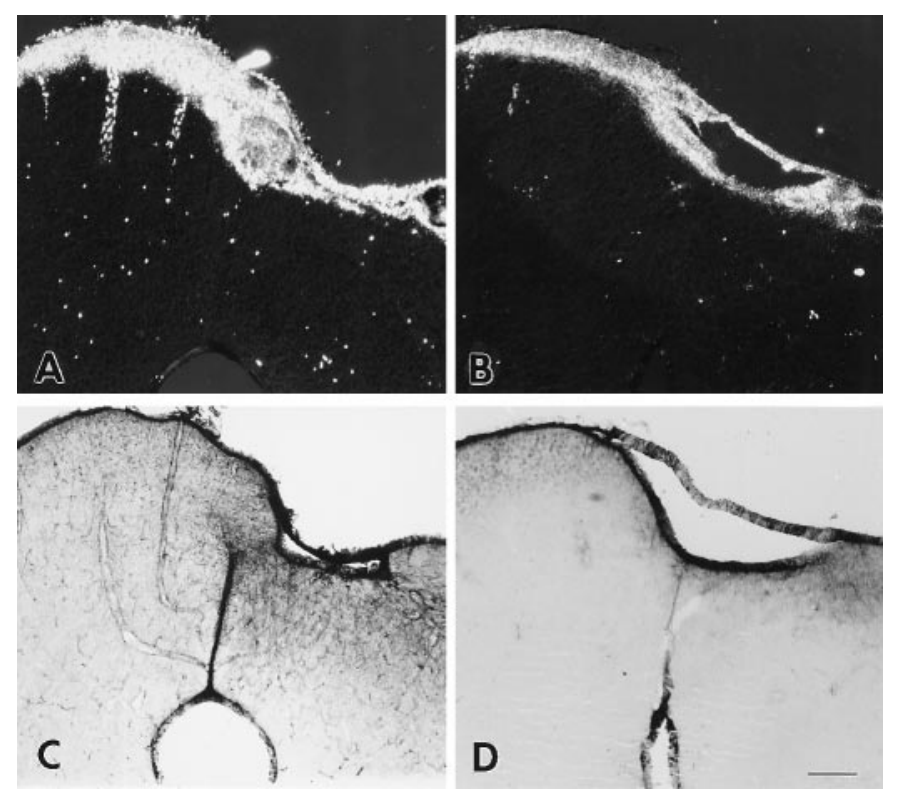

Figure 3. Two sets of adjacent sections through the tectum of two P8 animals ( $A$ and $C$ from one animal, $B$ and $D$ from the other) that had suffered unilateral (right side) tectal lesions on $\mathrm{P} 1$; their right eyes were removed at the same time. On P7, the left eyes were injected with HRP, and a day later the animals were killed. In each brain, one set of sections were reacted for visualizing the HRP and photographed with dark-field optics $(A, B)$, whereas immediately adjacent sections $(C, D)$ were immunostained with an antibody against GFAP, which permits visualization of glia. Note the HRP-labeled axons crossing the tectal midline along the membranous bridge that forms above the necrotic tissue cyst in the right SC (the necrotic tissue within the cyst falls out during histological processing) and also along a lower route that passes below the cyst over the remnant right tectal tissue. The complementary relationship between where retinal axons are able to travel and where the glial process are disrupted is especially obvious in $C$. Higher magnification views of the disrupted regions in $C$ and $D$ are depicted in Figure 5. Scale bar (in $D$ ): $A-D, 200 \mu \mathrm{m}$.

\section{Midline ultrastructure in the normal SC and in the tectal lesion cases}

In normal animals, ultrastructural examination of the pial processes of tectal midline glia revealed electron-lucent, radially oriented profiles that were rich in glycogen granules and mitochondria (see spared radial fibers in Fig. 6, which shows a micrograph from a lesioned animal). The distal tips of these processes were enlarged, forming end feet that attached at the basal lamina. On P6, small unmyelinated axons, many of which were likely collateral arbors of normal retinotectal fibers, could be identified, clustered in the upper layers of the developing SC; near the midline, these fibers were abutted against the radial processes. In experimental animals that had been subjected to heat-induced unilateral tectal lesions, ultrastructural examination documented a close interaction between axons and non-neuronal cells. This was especially evident in the tissue bridge that formed above the necrotic collicular tissue; immature glial processes that invaded this region had the ability to actively extend long ramified processes. The axons and their growth cones were closely apposed to these processes (Fig. 7).

\section{Undercutting the midline cells}

A second approach to damaging the pial processes of the midline glia, one that retained the integrity of the retinorecipient tectal zones, was to undercut the radial cells. This technique involved
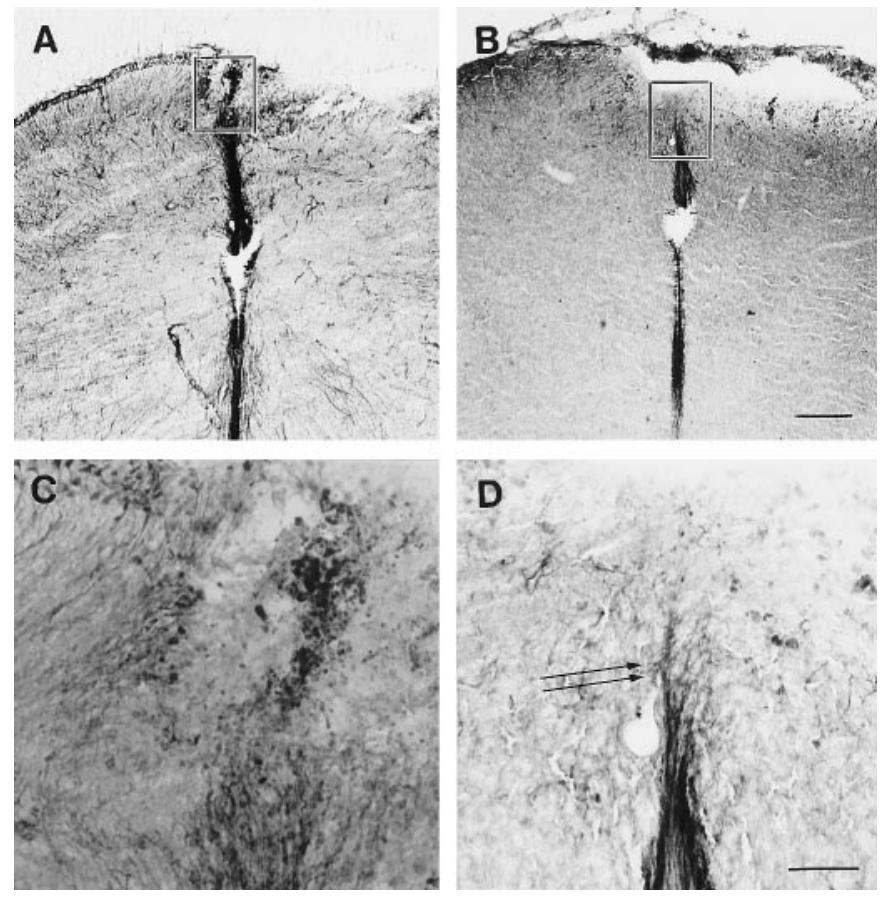

Figure 4. Coronal sections through the SC of two hamsters ( $A$ and $C$ from one animal, $B$ and $D$ from the other) that survived $18 \mathrm{hr}$ after suffering heat damage to one SC. Boxed areas in $A$ and $B$ are shown at higher magnification in $C$ and $D$, respectively. The damaged tissue has become necrotic (the cyst is especially noticeable over the right $\mathrm{SC}$ in $B$ ), and the disruption of distal process of midline glial cells is evident with immunostaining for vimentin $(A, C)$, as well as for $\operatorname{GFAP}(B, D)$. Arrows in $D$ point to the ends of some distal processes. Note end feet of lateral radial glia in upper left of $C$. Scale bars: (in $B$ ) A, B, $200 \mu \mathrm{m}$; (in $D$ ) $C, D$, $50 \mu \mathrm{m}$.

the insertion of a tungsten wire at the lateral edge of the left SC and pushing it medially toward the midbrain septum to sever the distal portions of the raphe glia from the cell body and more proximal processes (see Materials and Methods). In most cases, the wire track encroached slightly into the medial portion of the right SC (Fig. 8A). The right eye was also removed at the time of surgery. This increased the number of retinal axons that crossed over into the denervated (left) SC.

Eighteen hours after surgery, the horizontal cut made by the passage of the tungsten wire could be visualized in histological material (Fig. 8). Degradation of the severed distal processes was evident in tissue immunostained with the anti-vimentin antibody (Fig. $8 B$ ); however, the lower portions of the radial glial processes (below the wire cut) and the glial perikarya (located near the ventricular surface) appeared to remain viable. Over the next couple of weeks, the edges of the tissue along the wire track came together and could be identified by immunostaining for GFAP (Fig. 9A, arrowheads). The left SC was shrunken because of the removal of its contralateral retinal input at the time of neonatal surgery. Labeled retinal axons from the left eye could be followed to their normal zone of termination in the SGS of the right SC and were also seen streaming across the tectal midline into the SGS of the left SC (Fig. 9B,D). Adjacent sections were stained for visualizing HRP-labeled retinal axons or GFAP-reactivity. These documented a correlation at the midline between the zone in which severed pial processes of the raphe glia had been disrupted (Fig. 9A,C, double arrows) and the region over which retinal axons were able to navigate across the midline (Fig. 9B,D). It 

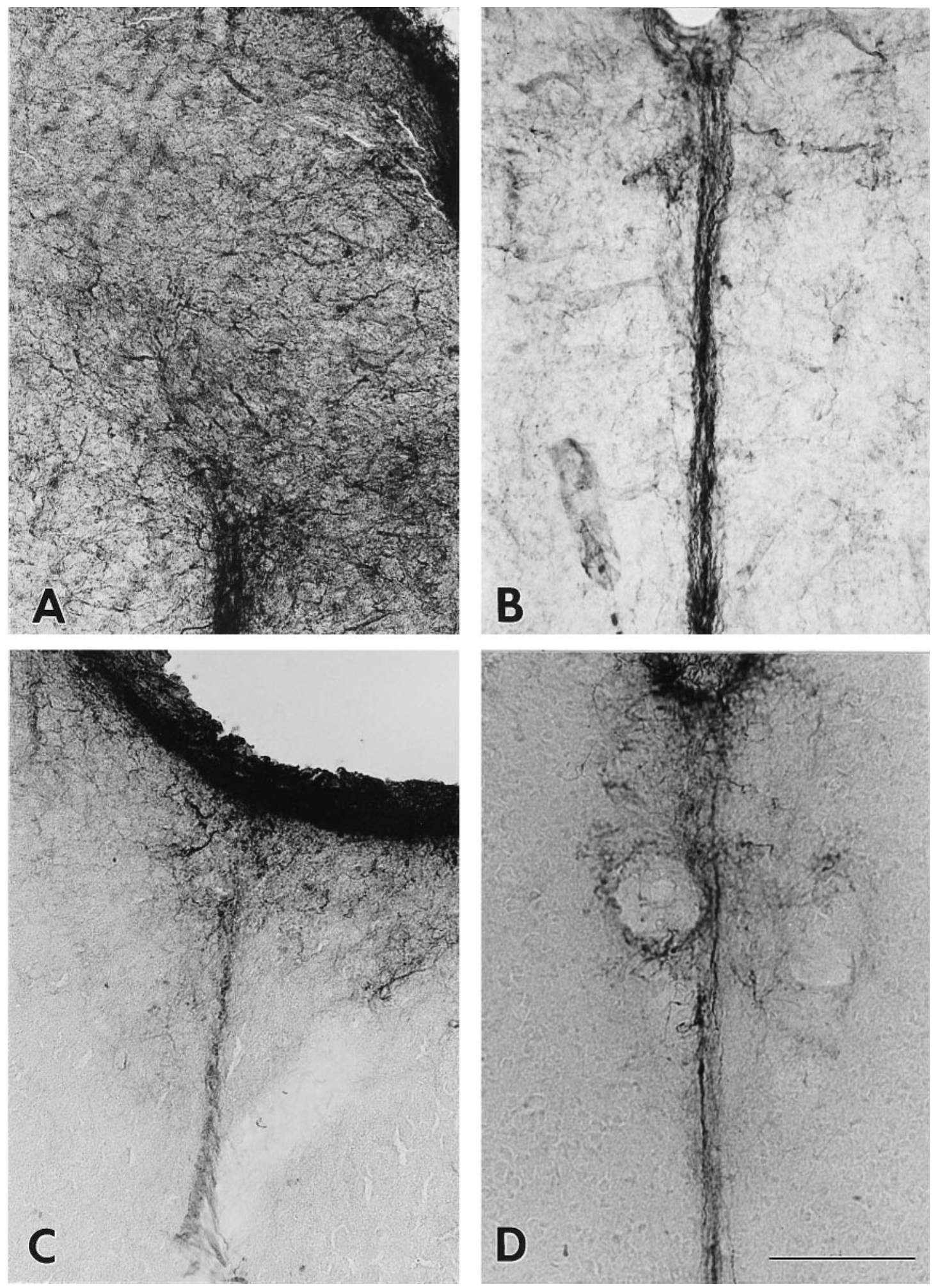

Figure 5. $A, C$, Higher magnification views of Figure $3 C, D$ to show the disruption of the distal processes of the midline glia. Comparable levels from the tectal midline of normal animals are shown in $B$ and $D$. Coronal sections immunostained with an antibody against GFAP. Scale bar (in $D$ ): $A-D, 100 \mu \mathrm{m}$.

should also be noted in Figure 9 that at the midline the ventralmost extent of retinal axons reached no further than the region beyond which the basal processes of the glia were intact. Sections from control animals (data not shown) documented that no recrossing of the midline was seen when the wire stopped short of the raphe glia or when the eye was removed but the midline was not undercut.

In two animals, midline cells were undercut on P1, the right eye was removed, and a solution of DiI was injected in the left eye via a trans-scleral approach. The animals were perfused on P3, and 


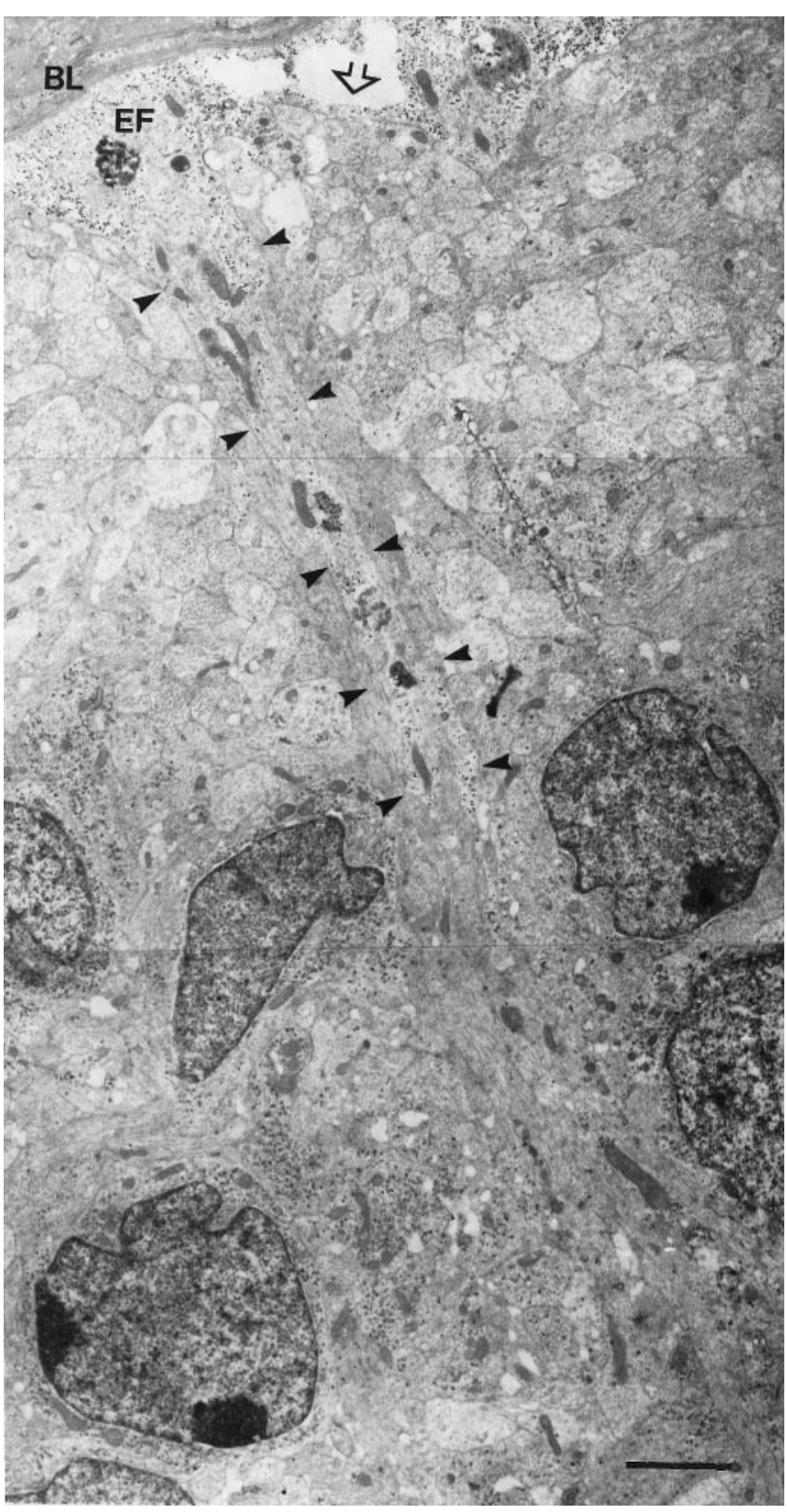

Figure 6. Electron micrograph of the midline roof plate in a hamster $<1$ $\mathrm{d}$ after a tectal lesion. Note the beginnings of the lesion cavity (open arrow) in one region, whereas a normal-looking raphe glial cell (arrowheads), comprised of an electron-lucent process, is still intact nearby. The end foot $(E F)$ is attached at the basal lamina $(B L)$; the basal processes of these cells extend (bottom right) toward the central canal. Scale bar, $1 \mu \mathrm{m}$.

crystals of DiA were placed along the upper surface of the aqueduct of Sylvius to visualize the radial glia in the postnatal SC. Two days later, the DiA labeling revealed the full extent of the radial fibers that had survived the wire cut; in the left SC, they stretched dorsally from the ventricle, stopping abruptly just below the optic fiber layer, at the point where their distal processes had been severed by the wire (Fig. $10 A, B$ ). At least up to $2 \mathrm{~d}$ after surgery, there was no indication of regeneration of the severed pial processes. In the same brains, DiI-labeled retinal axons could be followed from the left eye to the right SC. It was clear that even within $2 \mathrm{~d}$ of undercutting the midline cells, a few retinal pro-
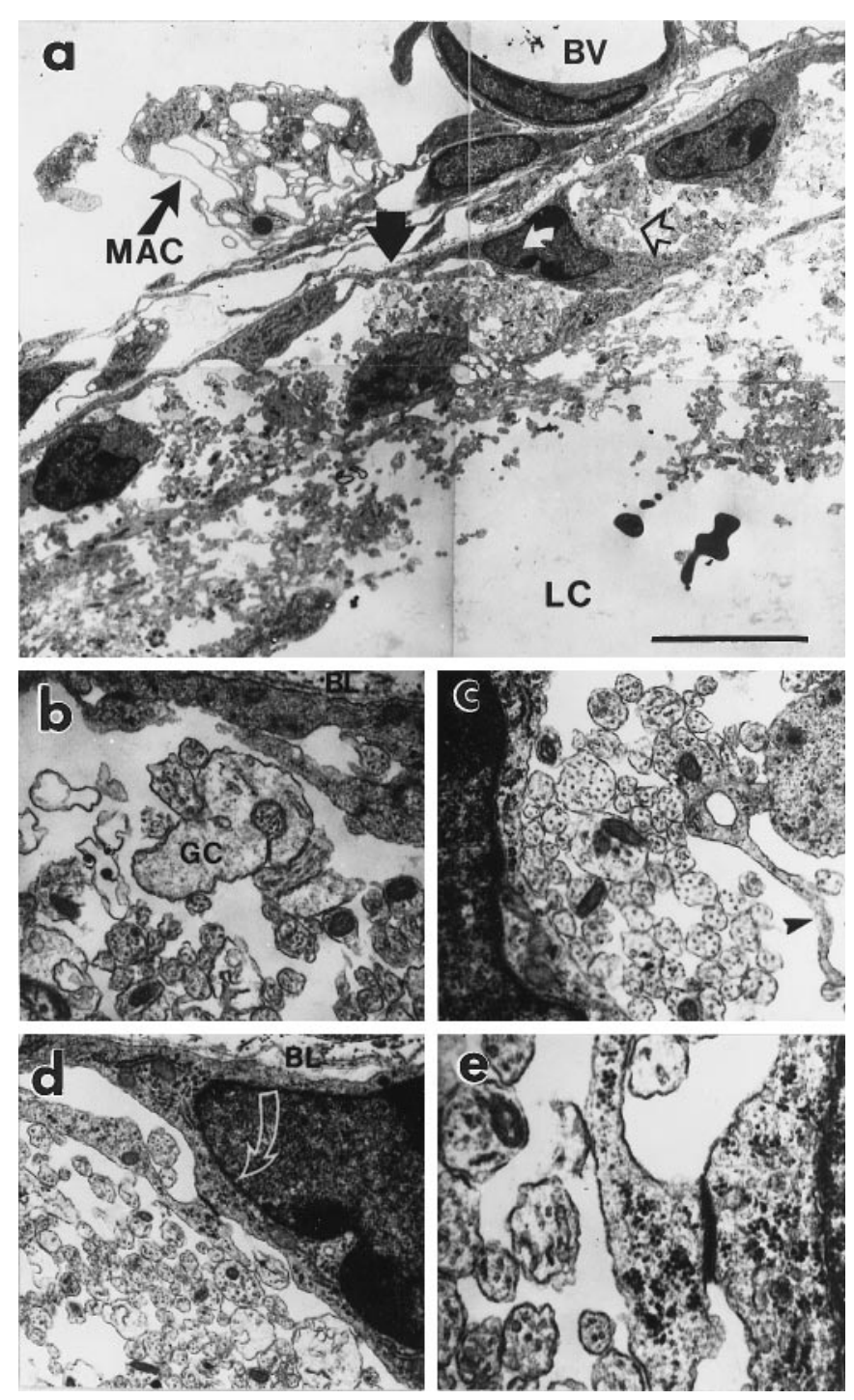

Figure 7. Electron micrographs of the tissue bridge that formed over the superficial SC in P6 animals that had been subjected to an heat lesion of the tectum on P0 or P1. $a$, Note the bundle of fasciculated axons (large open arrow) located between the glial cells (white arrow) that reconstitute the glial limiting membrane ( filled arrows). $M A C$, Macrophage; $B V$, blood vessel; $L C$, lesion cavity. $b$, Higher magnification of putative growth cone $(G C)$ that has wrapped itself around an axon; in the upper left of the photomicrograph, the basal lamina $(B L)$ on the surface of the tectal tissue is visible. $c$, Glial process (arrowhead), which may serve as a scaffolding for the growth of axons, that are regenerating across the tissue bridge. $d$, Close apposition of glial cells within the tissue bridge (curved open arrow), which are connected by adherens junctions, shown at higher magnification in $e$. Scale bar (in $a$ ): $a, 10 \mu \mathrm{m} ; b-d, 1 \mu \mathrm{m} ; e, 0.4 \mu \mathrm{m}$.

cesses had begun to cross the tectal midline and to enter the wrong (left) SC (Fig. 10C, curved arrows).

Double exposure photography using fluorescein and rhodamine filters documented a complementary relationship between the region in which the abnormal crossover of retinal axons occurred and the area over which the cut processes of the midline glia were withdrawn (Fig. 10). Note that these first few retinal axons that ventured across the midline were not fasciculated but seemed to travel individually; nor did they necessarily show a preference for growing along the pial surface, as do the earliest retinal fibers that enter the SC in the normal embryo (Jhaveri et 

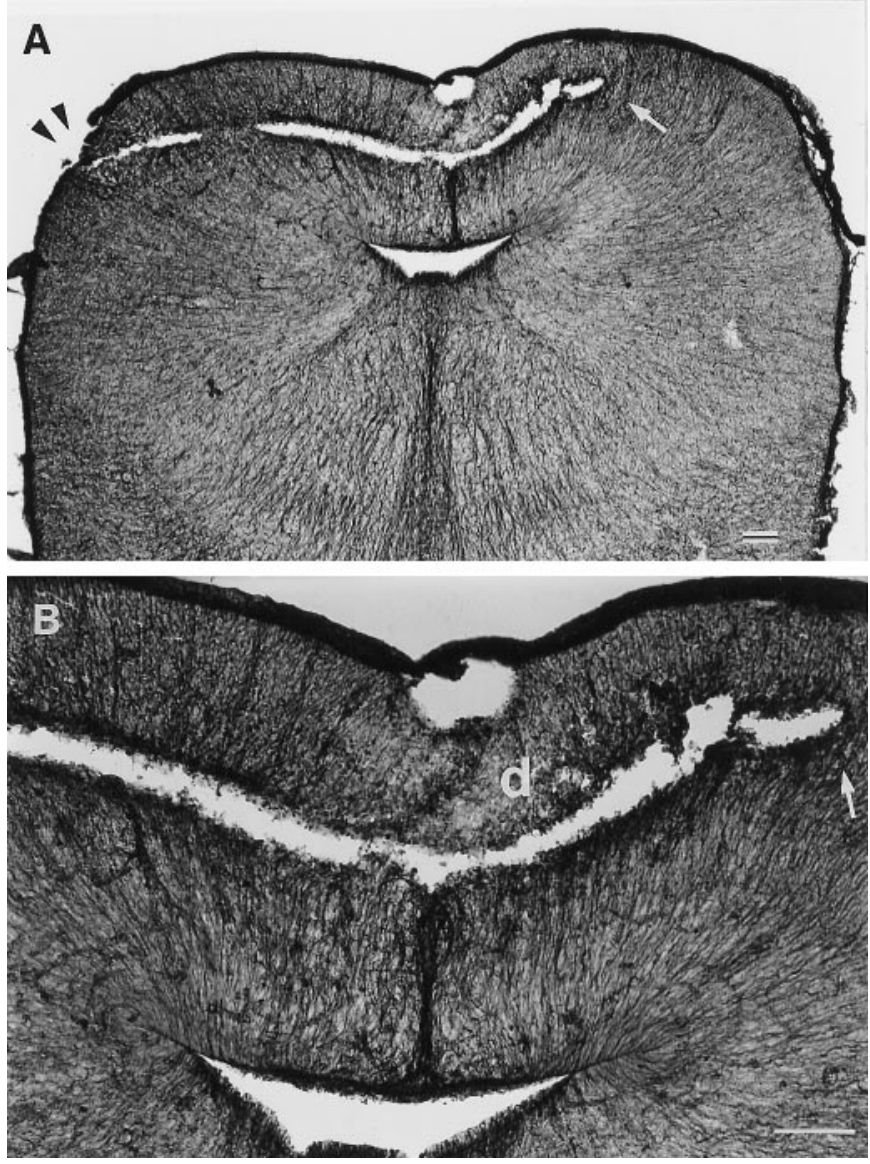

Figure 8. A horizontally oriented wire was used in this animal to undercut the pial processes of midline glia. The lateral to medial extent of the tract, including the overreach into the right $\mathrm{SC}(A, B$, white arrows $)$, is visible in this section. Note that the track remains below the retinorecipient layers and that within a short time after surgery, the distal processes of midline glia are already beginning to degenerate $(d)$. Scale bars, $100 \mu \mathrm{m}$.

al., 1991a). Recrossing retinal afferents were, instead, distributed throughout the gap created by the undercutting (Fig. 10C). We were able to trace a few crossing axons retrogradely from their terminals in the left SC and found that they also had small collateral branches in the "correct" SC (data not shown). Thus, it appears that at least at this early stage, retinal ganglion cell axons fated to terminate in the right SC might expand their target area by branching into the left SC but without relinquishing their normal territory.

The recrossing of the tectal midline by retinal axons was robust several days after the midline glia were damaged. By P14, retinal axons from the left eye were found to occupy one-half to twothirds of the mediolateral extent of the left SC (Fig. 9B,D); moreover, there was no obvious indication at this stage that they achieved this massive extra projection by a compensatory decrease in the density of projections to their appropriate termination zone in the right SC. If both eyes were left intact but the midline glia were cut, HRP-labeled retinal axons from the left eye terminated in the right SC and also crossed the midline, but the latter were restricted to the medial-most portion of the "wrong side" of the SC, indicating that there may be a competition between the two eyes for tectal terminal space (data not shown) (cf. So and Schneider, 1978).

Dorsal view reconstructions of the tectal midline in six animals
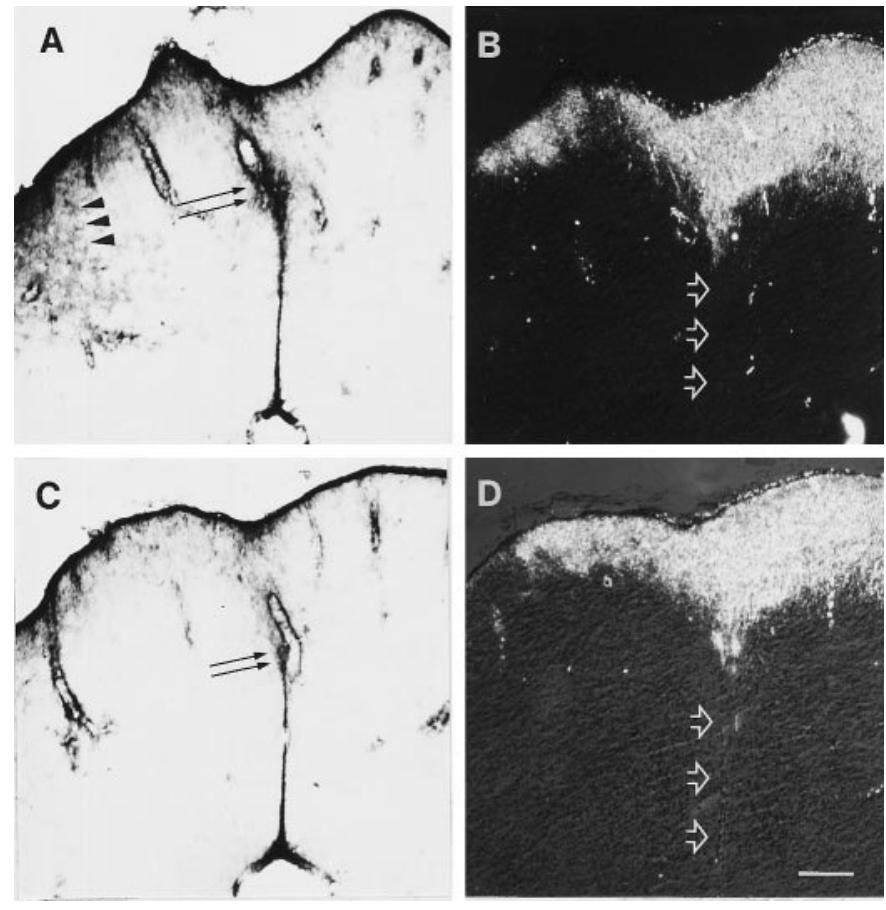

Figure 9. Pairs of immediately adjacent sections through the SC of two P14 brains ( $A$ and $B$ from one animal, $C$ and $D$ from the other) in which the midline processes were undercut on P1 and the left SC was denervated by removing the right eye. Coronal sections through the SC were immunostained with an anti-GFAP antibody $(A, C)$ or were reacted with tetramethylbenzidine to visualize HRP-labeled retinal axons originating in the remaining left eye $(B, D)$. The point at which the wire entered the left SC is delineated by gliosis ( $A$, arrowheads), as seen with GFAP immunostaining. Double thin arrows in $A$ and $C$ indicate the point above which the midline processes were severed. In $B$ and $D$, the distribution of HRP-labeled retinal axons is shown. Note that in both cases, the retinotectal projection to the right SC is targeted to normally retinorecipient layers, and a significant contingent of labeled retinal axons can be traced across the tectal midline into the SGS of the left SC. Open arrows in $B$ and $D$ indicate the position of the tectal roof plate. Scale bar (in $D$ ), $200 \mu \mathrm{m}$.

that had the raphe glia undercut documented that there was a mismatch between the total extent over which the glial processes were cut and the total extent over which retinal axons were detected crossing to the wrong SC. As illustrated in Figure 11, for all six cases the extent of the gap created by disruption of the glia was larger than the region of crossover of retinal fibers. Gaps varied in length from 300 to $960 \mu \mathrm{m}$, whereas the distance over which retinal fibers traversed ranged from 240 to $800 \mu \mathrm{m}$. This result was qualitatively verified in additional cases for which the midline was not reconstructed.

\section{DISCUSSION}

The spatiotemporal deployment of a group of glial cells at the tectal midline would permit them to subserve the unilateral confinement of retinotectal axons in normal animals (Fig. 12A) (Raedler et al., 1982; Barradas et al., 1989; Harvey et al., 1993; Wu et al., 1995). Lesion of one SC leads to an abnormal crossing of retinal afferents but only if the tectal midline is disrupted (Mustari and Lund, 1976; Hsiao and Schneider, 1978; Jen and Lund, 1979; Schneider et al., 1985). Here, we use two early lesion paradigms to document the direct involvement of the tectal raphe glia in the containment of retinal axons. With both perturbations, glial processes degenerate and retinal axons cross the collicular midline (Fig. 12B). 

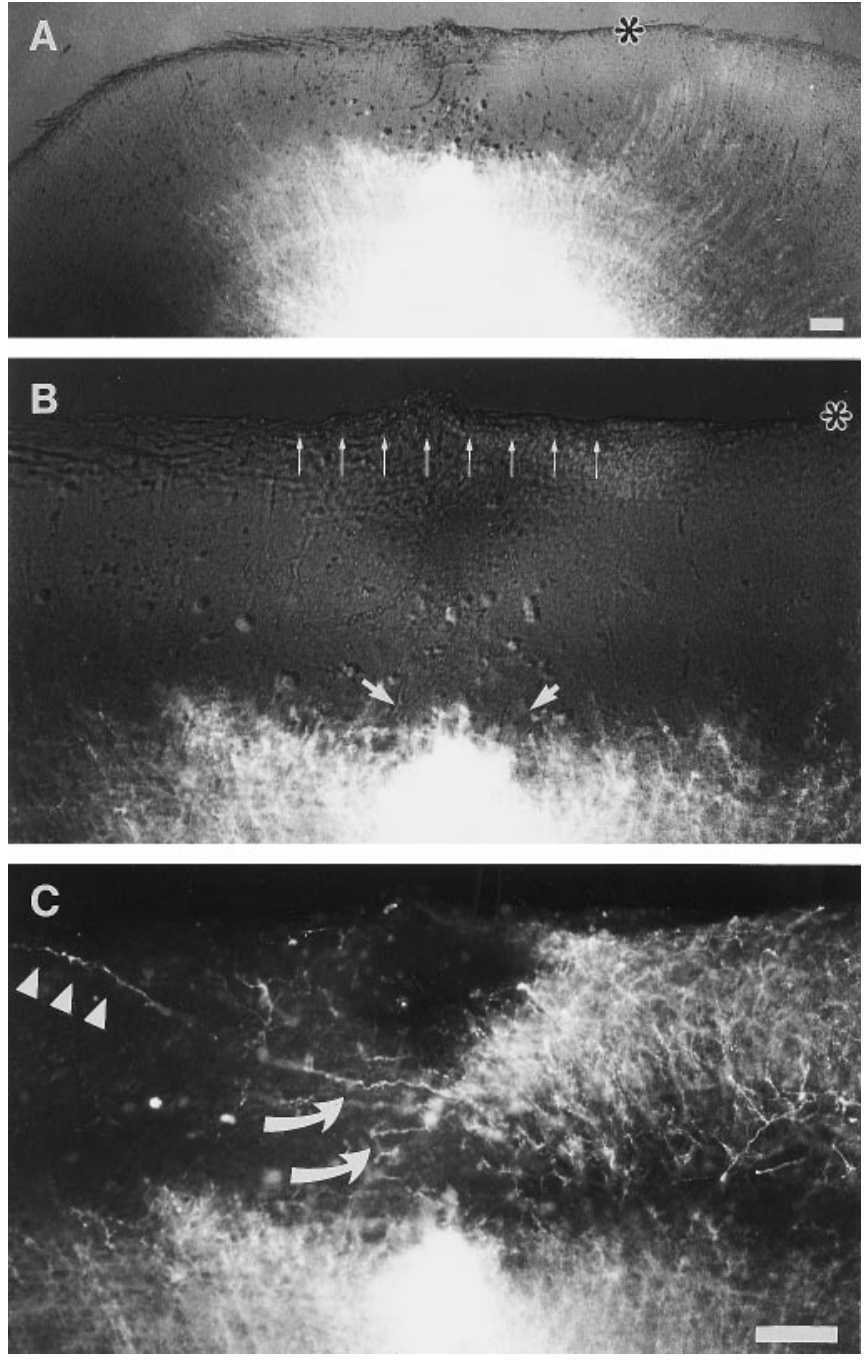

Figure 10. In this animal, the midline was undercut with a wire inserted into the left SC on P1; the wire was extended medially just past the midline (asterisk in $A$ depicts the farthest reach of the wire into the right $\mathrm{SC}$ ), and the right eye was removed at the time of the undercutting. DiI was injected into the left eye at the same time, and the animal was perfused $2 \mathrm{~d}$ later. DiA was placed in the dorsal wall of the ventricle. Coronal sections through the SC of this animal are photographed with a fluorescein filter, which reveals the DiA labeling. In $A$, the sections are additionally dimly transilluminated to show the tectal surface. The radial glia in the lateral portion of the right SC, lateral to the asterisk, are intact and can are dimly visible as they enter the superficial layers $(A) . B$ and $C$ show the same higher magnification view of the section shown in $A . B$ is viewed with a fluorescein filter and shows cut radial glia and midline glia (arrows). $C$ is a double exposure obtained first with use of a fluorescein and then with a rhodamine filter. Thus, in $C$, the distribution of DiIlabeled retinal axons is seen relative to the cut midline processes. White arrowheads in $C$ point to a retinal axon that has already grown several hundred micrometers into the wrong SC. Curved arrows point to retinal axons where they stream over the midline. Scale bars (in $A$ and $C$ ), $100 \mu \mathrm{m}$.

\section{Cells that colonize the midline of the neuraxis}

There is considerable speculation about the role of specialized cells in forming barriers against migrating neurons or against growing axons (Joosten and Gribnau, 1989; Silver et al., 1993; Heyman et al., 1995; Brunso-Bechtold and Henkel, 1996). In the spinal cord, interactions between gene products of the bone morphogenetic protein 4, sonic hedgehog, and related genes
(Liem et al., 1995; Jordan et al., 1997) may determine the formation of the roof plate and floor plate and affect growth patterns of sensory and motor projections (Ruiz i Altaba and Jessell, 1993; Dosch et al., 1997; Knecht and Harland, 1997; Mehler et al., 1997). Floor plate cells express a chemotropic factor that attracts axons of commissural neurons toward the midline (TessierLavigne et al., 1988; Kennedy et al., 1994; Colamarino and Tessier-Lavigne, 1995a). Roof plate glia are implicated in blockading dorsal column fibers from contralateral encroachment (Snow et al., 1990a,b). Cells in the optic chiasm are involved in the guidance of temporal and nasal retinal axons (Silver, 1984; Godement and Mason, 1993; Wizenmann et al., 1993). Specialized glia also form boundaries in regions that lie off the midline (Steindler et al., 1990; Silver et al., 1993; Steindler, 1993; Heyman et al., 1995). However, apart from the work on the crossing of ventral commissural axons through the floor plate, the relationship between midline cells and the guidance of axons that encounter them has been correlative. Here, we show a causal relationship between disruption of the tectal midline glia and a rerouting of retinotectal afferents.

\section{Permissive versus inductive mechanisms for retinal axon crossing}

After heat damage to the developing SC, a membranous bridge forms over the necrotic tissue (So and Schneider, 1978; So, 1979; Harvey et al., 1986). This structure is rich in GFAP-positive glial processes, many of which have a close spatial relationship with growing tectal afferents (Figs. 3D, 6, 7). Glia that invade the bridge likely provide the substrate on which retinal axons navigate across the tectal midline. Because we never see a bridge without retinal axons coursing along it, its substrate is likely both permissive and instructive for the grow th of retinotectal afferents. However, such an influence is not easy to quantify because of technical difficulties in retaining bridge tissue during histological processing. Retinal axons also cross via a second route, under the necrotic tissue, through the area in which the midline glia have been undercut. Midline reconstructions reveal that the region of damage and the region over which retinal axons cross are not coextensive. The axons occupy only a fraction of the gap in the roof plate and do not grow across any part of the tectal midline where the raphe glia are not disrupted. Collectively, these observations indicate that disruption of glial processes leads to the formation of a permissive, but not instructive, substrate for the growth of immature retinal axons (So and Schneider, 1978; Kapfhammer et al., 1992). Thus, additional signals must be involved in determining exactly where retinal axons travel within the disrupted zone (see below).

\section{Specificity of glial barriers and putative molecular bases for the barrier}

A critical question concerns the specificity of glial barriers in relation to different axon systems. Barriers that block growth of only certain fiber populations and ones that universally block all growing fibers may function in the brain. For instance, retinotectal axons do not cross the tectal midline, but contralaterally projecting fibers in the tectal commissure are able to successfully navigate across this region. This may be either because each system is differentially responsive to the midline glia, or because intertectal axons cross the midline before glial differentiation (Jhaveri, 1993a,b) and before the expression of putative inhibitory molecules along the tectal roof plate. Similarly, dorsal spinal commissural axons cross the roof plate after the ingrowth and 


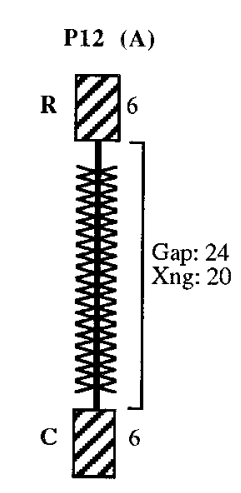

Gap: $\quad 960 \mu \mathrm{m}$
Cross: $800 \mu \mathrm{m}$

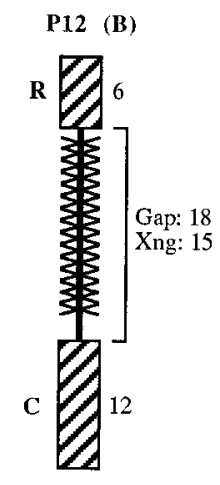

Gap: $\quad 720 \mu \mathrm{m}$ Cross: $600 \mu \mathrm{m}$

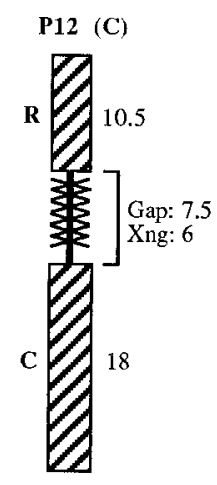

Gap: $\quad 300 \mu \mathrm{m}$ Cross: $240 \mu \mathrm{m}$
P12 (D)

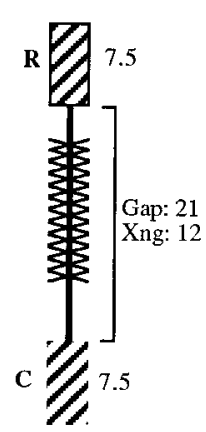

Gap: $\quad 840 \mu \mathrm{m}$
Figure 11. Schematic dorsal view reconstructions of the tectal midlines from animals (ages P12 and P14 at time of perfusion) that had the raphe glia undercut on P1. The number of sections through the rostral $(R)$ to caudal $(C)$ extent of each SC was counted; the extent of the midline is depicted along a line (arbitrary units). The region of each midline along which the distal processes of the raphe glia were observed as being intact is marked with hatching; the extent of each midline where the pial processes were disrupted is depicted with a thick straight line; the region of each midline over which retinal axons were seen crossing abnormally to the opposite side is marked with Xs. Numbers (in arbitrary units) representing the length of the rostrocaudal extent of the undamaged region for the gap (Gap) created by disrupting the midline glia and for the length of the midline over which retinal axons are seen crossing (Xng) are indicated. The length (in micrometers) for the disrupted region (Gap) and for the distance over which retinal crossover is observed (Cross) are provided at the bottom of each reconstruction.

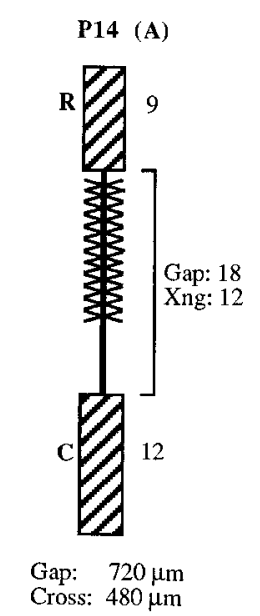

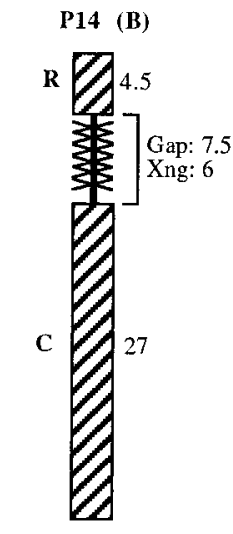

Gap: $300 \mu \mathrm{m}$ Cross: $240 \mu \mathrm{m}$

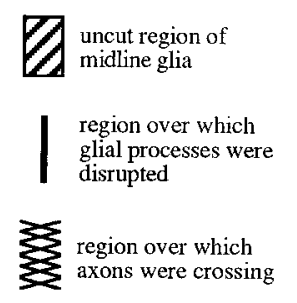

unilateral compartmentalization of sensory axons in dorsal columns when putative axon-inhibitory molecules are no longer detected along the roof plate. These observations suggest that the barrier function of midline cells might be universal and that if axon systems were to bypass the blockade, they would be compelled to grow through before its functional maturation or after its ephemeral expression of inhibitory molecules has diminished. One could argue that selective decussation of nasal (but not temporal) retinal axons at the optic chiasm belies this notion: axons from nasal and temporal retina approach the ventral midline at approximately the same time, but each interacts differentially with chiasm cells (Godement and Mason, 1993; Sretavan et al., 1994). However, ipsilateral deflection of temporal axons occurs early during chiasm formation (Drager, 1985; Reese and Colello, 1992; Baker and Reese, 1993); later, both temporal and nasal retinal axons project contralaterally, again invoking temporally variable factors in the decision to cross or not. Also, ipsilaterally directed corticotectal axons cross the tectal midline after deafferentation of the contralateral colliculus but in the absence of any damage to the midline glia (Mustari and Lund, 1976; Jen et al., 1978; Rhoades and Chalupa, 1978; Land et al., 1984); however, the expanded corticotectal projection crosses the midline at deeper levels of the SC (Jen et al., 1978; Harvey and Worthington, 1990), where retinal fibers do not normally reach.

The molecular bases for tectal midline barrier functions are unknown, but PGs have been incriminated. In vivo, some PGs are present in regions in which axons do not grow (Snow et al., 1990a,b; Cole and McCabe, 1991; McKeon et al., 1991; McCabe and Cole, 1992; Gonzalez et al., 1993; Pindzola et al., 1993; Silver et al., 1993; Heyman et al., 1995; Brunso-Bechtold and Henkel, 1996; Jhaveri and Hoffman-Kim, 1996; Reese et al., 1997). In the developing SC, sulfated PGs are detected in tissue harvested from the midline (where retinal axons do not grow) and also from the lateral tectum (where retinal axons do extend). Biochemical characterization shows that PG core proteins are similar at the tectal midline and laterally but that those along the midline are more heavily glycosylated (Hoffman-Kim et al., 1996, 1998). This suggests that the glycosaminoglycans, and not the protein cores, are likely participants in the barrier function. In vitro observations of retinal explants growing on glial carpets also confirm that the glia harvested from the midline region are less supportive of retinal axon extension (Young et al., 1997). Thus, it is likely that PGs on glial cells or in the extracellular matrix surrounding glial cells subserve the avoidance of the tectal midline by retinal axons. Garcia-Abreu et al. (1995, 1996) document a differential PG content in glia harvested from the middle versus lateral thirds of the midbrain and show that tectal neurons exhibit differences in neurite outgrowth patterns on the two types of glia.

Diffusible molecules such as netrins, secreted by floor plate cells, can act as chemoattractants and chemorepellants to guide 

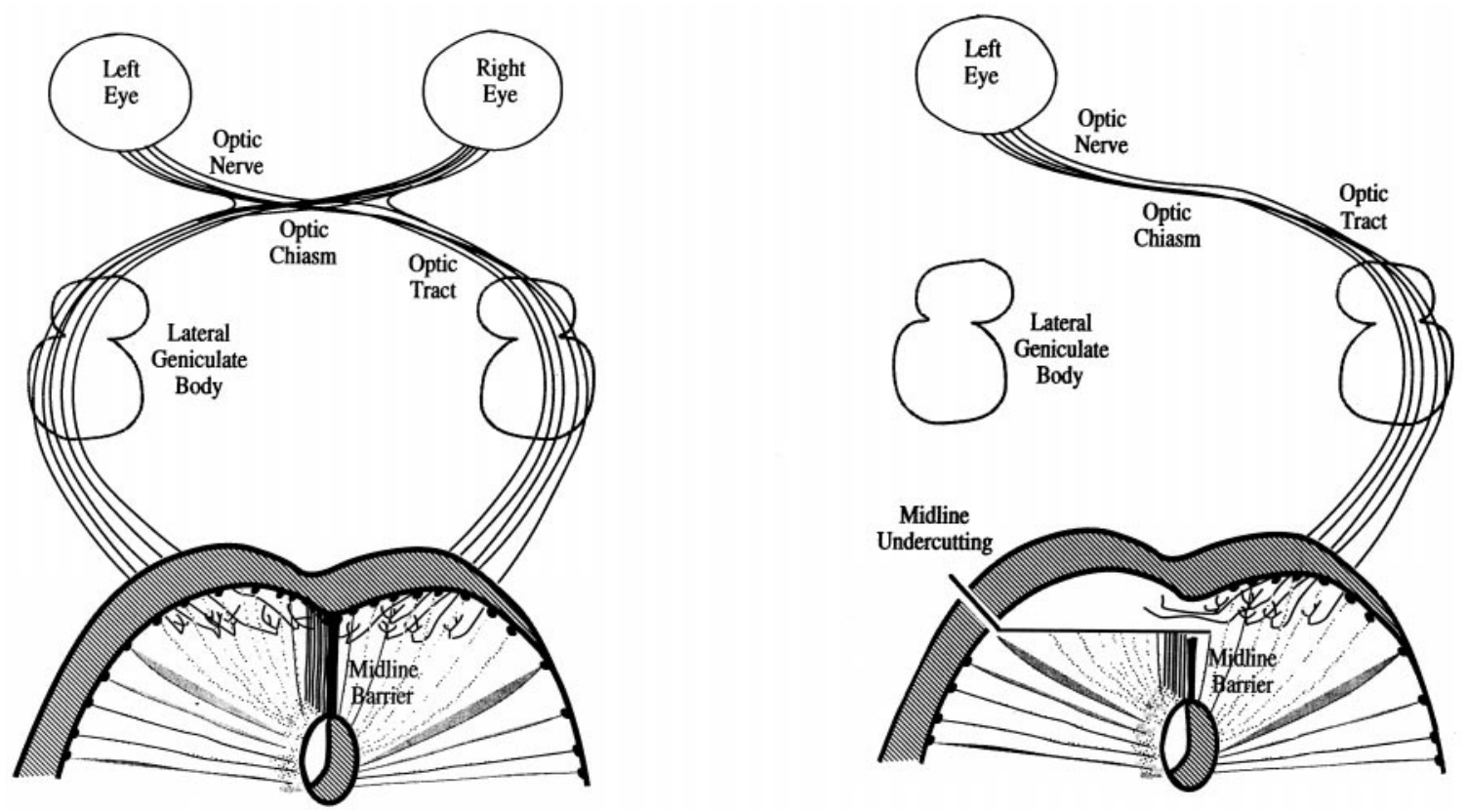

Figure 12. Cartoon summary of conclusions from this study. Left, The course of retinal axons as they leave the eye, pass through the lateral geniculate body, and approach the tectal midline is shown. Retinal axons stop at the midline glia, and the laterality of the retinotectal projection is maintained in normal animals. Right, The midline cells have been undercut in the neonatal animal, and one eye is removed. This releases the midline blockade, and a crossover of retinal axons to the opposite SC is seen in the region in which pial processes of the midline glia have been damaged.

the growth of specific afferent systems (Colamarino and TessierLavigne, 1995b). Mice deficient in netrin (Serafini et al., 1996; Guthrie, 1997) or its receptor (Fazeli et al., 1997) show disrupted decussation of some axons but not of others, indicating a specificity of responses by different afferents to this class of molecules. A diffusible factor that repels commissural axons has been reported for the spinal cord roof plate (Augsburger et al., 1996), which must act in concert with chemoattractants released by the floor plate to guide the growth of the ventrally crossing fibers. For the hamster SC, evidence points to an inhibitory role for PGs (membrane bound or secreted into the extraneuronal matrix) in relation to retinal axon growth (see above). However, the observation that retinal axons do not completely fill the gap created by disruption of the midline glia (Fig. 11) suggests that, at least in animals with a damaged midline, a second diffusible chemorepellant substance released by these glia is also at work. If such a diffusible factor does emanate from the roof plate, perhaps it is not a very potent player during the normal development of the retinotectal fibers given the fact that many of these fibers encroach so close to the tectal midline. Finally, the recent discovery of genes such as robo (Kidd et al., 1998a,b) and sax3 (Zallen et al., 1998) demonstrates that the genetic make-up of afferent neurons, and not just the molecular composition of the extraneuronal environment, is an additional factor in determining whether or not successful decussation of axons can take place.

\section{REFERENCES}

Abbott NJ (1991) Permeability and transport of glial blood-brain barriers. Ann NY Acad Sci 633:378-394.

Aguayo AJ, Bray GM, Rasminsky M, Zwimpfer T, Carter DA, VidalSanz M (1990) Synaptic connections made by axons regenerating in the central nervous system of adult mammals. J Exp Biol 153:199-224.

Augsberger A, Schuchardt A, Hoskins S, Dodd J (1996) Repulsion of spinal commissural axons by a diff usible factor from the roof plate. Soc Neurosci Abstr 22:1473.
Baker GE, Reese BE (1993) The chiasmatic course of temporal retinal axons during development. J Comp Neurol 330:95-104.

Barradas PC, Cavalcante LA, Mendez-Otero R, Vieira MA (1989) Astroglial differentiation in the opossum superior colliculus. Glia 2:103-111.

Bennett-Clarke CA, Leslie MJ, Lane RD, Rhoades RW (1994) Effect of serotonin depletion on vibrissa-related patterns of thalamic afferents in the rat's somatosensory cortex. J Neurosci 14:7594-7607.

Blue ME, Erzurumlu RS, Jhaveri S (1991) A comparison of pattern formation by thalamocortical and serotonergic afferents in the rat barrel field cortex. Cereb Cortex 1:380-389.

Brunso-Bechtold JK, Henkel CK (1996) Axon decussation and midline glia in the developing ferret auditory hindbrain. Prog Brain Res 108:165-181.

Chiquet M (1989) Neurite growth inhibition by CNS myelin proteins: a mechanism to confine fiber tracts? Trends Neurosci 12:1-3.

Colamarino SA, Tessier-Lavigne M (1995a) The role of the floor plate in axon guidance. Annu Rev Neurosci 18:497-529.

Colamarino SA, Tessier-Lavigne M (1995b) The axonal chemoattractant netrin-1 is also a chemorepellent for trochlear motor axons. Cell 19:621-629.

Cole GJ, McCabe CF (1991) Identification of a developmentally regulated keratan sulfate proteoglycan that inhibits cell adhesion and neurite outgrowth. Neuron 7:1007-1018.

Davies SJA, Fitch MT, Memberg SP, Hall AK, Raisman G, Silver J (1997) Regeneration of adult axons in white matter tracts of the central nervous system. Nature 390:680-683.

Dodd J, Jessell TM (1988) Axon guidance and the patterning of neuronal projections in vertebrates. Science 242:692-699.

Dosch R, Gawantka V, Delius H, Blumenstock C, Niehrs C (1997) Bmp-4 acts as a morphogen in dorsoventral mesoderm patterning in Xenopus. Development 124:2325-2334.

Drager UC (1985) Birth dates of retinal ganglion cells giving rise to the crossed and uncrossed optic projections in the mouse. Proc R Soc Lond B Biol Sci 224:57-77.

Fazeli A, Dickinson SL, Hermiston ML, Tighe RV, Steen RG, Small CG (1997) Phenotype of mice lacking functional deleted in colorectal cancer (Dcc) gene. Nature 386:796-804.

Garcia-Abreu J, Neto VM, Carvallho SL, Cavalcante LA (1995) Re- 
gionally specific properties of midbrain glia. I. Interactions with midbrain neurons. J Neurosci 40:471-477.

Garcia-Abreu J, Silva LCF, Tovar FF, Onofre GR, Cavalcante LA, Neto VM (1996) Compartmental distribution of sulfated glycosaminoglycans in lateral and medial midbrain astroglial cultures. Glia 17:339-344.

Godement P, Mason CA (1993) Guidance of retinal fibers in the optic chiasm. Perspect Dev Neurobiol 1:217-225.

Godement P, Salaun J, Mason CA (1990) Retinal axon pathfinding in the optic chiasm: divergence of crossed and uncrossed fibers. Neuron 5:173-186.

Gonzalez M de L, Malemud CJ, Silver J (1993) Role of astroglial extracellular matrix in the formation of rat olfactory bulb glomeruli. Exp Neurol 123:91-105.

Guthrie S (1997) Axon guidance: netrin receptors are revealed. Curr Biol 7:R6-R9.

Harvey AR, Worthington DR (1990) The projection from different cortical areas to the rat superior colliculus. J Comp Neurol 298:281-292.

Harvey AR, Gan SK, Dyson SE (1986) Regrowth of retinal axons after lesions of the brachium and pretectal region in the rat. Brain Res 368:141-147.

Harvey AR, Plant GW, Kent AW (1993) The distribution of astrocytes, oligodendroglia and myelin in normal and transplanted rat superior colliculus: an immunohistochemical study. J Neural Transplant Plast 4:1-14.

Hatten ME (1990) Riding the glial monorail: a common mechanism for glial-guided neuronal migration in different regions of the developing mammalian brain. Trends Neurosci 13:179-184.

Heyman I, Faissner A, Lumsden A (1995) Cell and matrix specializations of rhombomere boundaries. Dev Dyn 204:301-315.

Hoffman-Kim D, Lander A, Jhaveri S (1996) Regional differences in tectal chondroitin sulfate expression reflect differential rates of glycosaminoglycan biosynthesis. Soc Neurosci Abstr 22:34.

Hoffman-Kim D, Lander A, Jhaveri S (1998) Patterns of tectal chondroitin sulfate immunoreactivity in the developing tectum reflect regional differences in glycosaminoglycan biosynthesis. J Neurosci 18:5881-5890.

Hsiao KK-J, Schneider GE (1978) Neonatal hamster eye enucleation and tectal midline damage: effects of partial collicular ablation on retinotectal projections. Soc Neurosci Abstr 4:474.

Jen LS, Lund RD (1979) Intertectal crossing of optic axons after tectal fusion in neonatal rats. Brain Res 178:99-105.

Jen LS, Lund RD, Boles J (1978) Further studies on the crossed visual corticotectal pathway in rats. Exp Brain Res 33:405-414.

Jhaveri S (1993a) Midline glia of the developing tectum: a barrier for developing retinal axons. Perspect Dev Neurobiol 1:237-243.

Jhaveri S (1993b) Proteoglycan expression by tectal midline glia in relation to the growth of retinotectal and intertectal axons in developing hamsters. Soc Neurosci Abstr 19:1086.

Jhaveri S, Hoffman-Kim D (1996) Unilateral containment of retinal axons by tectal glia: a role for proteoglycans. Prog Brain Res 108:134-148.

Jhaveri S, Carman L, Hahm JO (1988) Visualizing anterogradely transported HRP by use of TMB histochemistry: comparison of the TMBSNF and TMB-AHM methods. J Histochem Cytochem 36:103-105.

Jhaveri S, Schneider GE, Erzurumlu RS (1991a) Axonal plasticity in the context of development. In: Development and plasticity of the visual system (Cronly-Dillon JR, ed), pp 232-256. London: Macmillan.

Jhaveri S, Erzurumlu RS, Crossin K (1991b) Barrel construction in rodent neocortex: role of thalamic afferents versus extracellular matrix molecules. Proc Natl Acad Sci USA 88:4489-4493.

Jhaveri S, Erzurumlu RS, Friedman B, Schneider GE (1992) Oligodendrocytes and myelin formation along the optic tract of the developing hamster: an immunohistochemical study using the rip antibody. Glia 6:138-148.

Joosten EAJ, Gribnau AAM (1989) Astrocytes and guidance of outgrowing corticospinal tract axons in the rat. An immunocytochemical study using anti-vimentin and anti-glial fibrillary acidic protein. Neuroscience 31:439-452.

Jordan J, Bottner M, Schluesener HJ, Unsicker K, Krieglstein K (1997) Bone morphogenetic proteins: neurotrophic roles for midbrain dopaminergic neurons and implications of astroglial cells. Eur J Neurosci 9:1699-1709.

Kapfhammer JP, Schwab ME (1994) Increased expression of the growth-associated protein GAP-43 in the myelin-free rat spinal cord. Eur J Neurosci 6:403-411.

Kapfhammer JP, Schwab ME, Schneider GE (1992) Antibody neutral- ization of neurite growth inhibitors from oligodendrocytes results in expanded pattern of postnatally sprouting retinocollicular axons. J Neurosci 12:2112-2119.

Kennedy TE, Serafini T, de la Torre JR, Tessier-Lavigne M (1994) Netrins are diffusible chemotropic factors for commissural axons in the embryonic spinal cord. Cell 78:425-435.

Kidd T, Brose K, Mitchell KJ, Fetter RD, Tessier-Lavigne M, Goodman CS, Tear G (1998a) Roundabout controls axon crossing of the CNS midline and defines a novel subfamily of evolutionarily conserved guidance receptors. Cell 92:205-215.

Kidd T, Russell C, Goodman CS, Tear G (1998b) Dosage-sensitive and complementary functions of roundabout and commissureless control axon crossing of the CNS midline. Neuron 20:25-33.

Knecht AK, Harland RM (1997) Mechanisms of dorsal-ventral patterning in noggin-induced neural tissue. Development 124:2477-2488.

Land PW, Rose LL, Harvey AR, Liverman SA (1984) Neonatal auditory cortex lesions result in aberrant crossed corticotectal and corticothalamic projections in rats. Dev Brain Res 12:126-130.

Liem Jr KF, Tremml G, Roelink H, Jessell TM (1995) Dorsal differentiation of neural plate cells induced by BMP-mediated signals from epidermal ectoderm. Cell 82:969-979.

McCabe CF, Cole GJ (1992) Expression of the barrier-associated proteins EAP-300 and claustrin in the developing central nervous system. Dev Brain Res 70:9-24.

McKeon RJ, Schreiber RC, Rudge JS, Silver J (1991) Reduction of neurite outgrowth in a model of glial scarring following CNS injury is correlated with the expression of inhibitory molecules on reactive astrocytes. J Neurosci 11:3398-3411.

Mehler MF, Mabie PC, Zhang D, Kessler JA (1997) Bone morphogenetic proteins in the nervous system. Trends Neurosci 20:309-317.

Muller CM, Best J (1989) Ocular dominance plasticity in adult cat visual cortex after transplantation of cultured astrocytes. Nature 342:427-430.

Mustari MJ, Lund RD (1976) An aberrant crossed visual corticotectal pathway in albino rats. Brain Res 112:37-44.

Patterson PH (1988) On the importance of being inhibited, or saying no to growth cones. Neuron 1:264-267.

Pindzola RR, Doller C, Silver J (1993) Putative inhibitory extracellular matrix molecules at the dorsal root entry zone of the spinal cord during development and after root and sciatic nerve lesions. Dev Biol 156:34-48.

Raedler E, Raedler A, Wegener G (1982) The median ventricular formation. Anat Embryol 165:377-387.

Reese BE, Colello RJ (1992) Neurogenesis in the retinal ganglion cell layer of the rat. Neuroscience 46:419-429.

Reese BE, Johnson PT, Hocking DR, Bolles AB (1997) Chronotopic fiber reordering and the distribution of cell adhesion and extracellular matrix molecules in the optic pathway of fetal ferrets. J Comp Neurol 380:355-372.

Rhoades RW, Chalupa LM (1978) Functional and anatomical consequences of neonatal visual cortical damage in superior colliculus of the golden hamster. J Neurophysiol 41:1466-1494.

Ruiz i Altaba A, Jessell TM (1993) Midline cells and the organization of the vertebrate neuraxis. Curr Opin Genet Dev 3:633-640.

Schachner M (1991) Cell surface recognition and neuron-glia interactions. Ann NY Acad Sci 633:105-112.

Schlagger BL, O'Leary DD (1994) Early development of the somatotopic map and barrel patterning in rat somatosensory cortex. J Comp Neurol 346:80-96.

Schneider GE (1973) Early lesions of superior colliculus: factors affecting the formation of abnormal retinal projections. Brain Behav Evol 8:73-109.

Schneider GE, Jhaveri S, Edwards MA, So KF (1985) Regeneration, re-routing, and redistribution of axons after early lesions: changes with age, and functional impact. In: Recent achievements in restorative neurology. I. Upper motor neuron functions and disfunctions (Eccles JC, Dimitrijevic MR, eds), pp 291-309. Basel, Switzerland: Karger.

Schwab ME (1990) Myelin-associated inhibitors of neurite growth and regeneration in the CNS. Trends Neurosci 13:452-456.

Schwab ME, Schnell L (1991) Channeling of developing rat corticospinal tract axons by myelin-associated neurite growth inhibitors. J Neurosci 11:709-721.

Schwab ME, Kapf hammer JP, Bandtlow CE (1993) Inhibitors of neurite growth. Annu Rev Neurosci 16:565-595.

Schwegler G, Schwab ME, Kapfhammer JP (1995) Increased collateral 
sprouting of primary afferents in the myelin-free spinal cord. J Neurosci 15:2756-2767.

Serafini T, Colamarino SA, Leonardo ED, Wang H, Beddington R, Skarnes WC, Tessier-Lavigne M (1996) Netrin-1 is required for commissural axon guidance in the developing vertebrate nervous system. Cell 87:1001-1014.

Silver J (1984) Studies on the factors that govern directionality of axonal growth in the embryonic optic nerve and at the chiasm of mice. J Comp Neurol 223:238-251.

Silver J, Rutishauser U (1984) Guidance of optic axons in vivo by a preformed adhesive pathway on neuroepithelial endfeet. Dev Biol 106:485-499.

Silver J, Edwards MA, Levitt P (1993) Immunocytochemical demonstration of early appearing astroglial structures that form boundaries and pathways along axon tracts in the fetal brain. J Comp Neurol 328:415-436.

Singer M, Nordlander R, Egar M (1979) Axonal guidance during embryogenesis and regeneration in the spinal cord of the newt: the blueprint hypothesis of neuronal pathway patterning. J Comp Neurol 185:1-22.

Snow DM, Steindler DA, Silver J (1990a) Molecular and cellular characterization of the glial roof plate of the spinal cord and optic tectum: a possible role for a proteoglycan in the development of an axon barrier. Dev Biol 138:359-376.

Snow DM, Lemmon V, Carrino DA, Caplan AI, Silver J (1990b) Sulfated proteoglycans in astroglial barriers inhibit neurite outgrowth in vitro. Exp Neurol 109:111-130.

So KF (1979) Development of abnormal recrossing retinotectal projections after superior colliculus lesions in newborn Syrian hamsters. J Comp Neurol 186:241-258.

So KF, Schneider GE (1978) Abnormal recrossing retinotectal projections after early lesions in Syrian hamsters: age-related effects. Brain Res 147:277-295.

Sretavan DW, Feng L, Pure E, Reichardt LF (1994) Embryonic neurons of the developing optic chiasm express L1 and CD44, cell surface molecules with opposing effects on retinal axon growth. Neuron 12:957-975.
Sretavan DW, Pure E, Siegel MW, Reichardt LF (1995) Disruption of retinal axon ingrowth by ablation of embryonic mouse optic chiasm neurons. Science 269:98-101.

Steindler DA (1993) Glial boundaries in the developing nervous system. Annu Rev Neurosci 16:445-470.

Steindler DA, Cooper NGF (1987) Glial and glycoconjugate boundaries during postnatal development of the central nervous system. Dev Brain Res 36:27-38.

Steindler DA, Cooper NGF, Faissner A, Schachner M (1989) Boundaries defined by adhesion molecules during development of the cerebral cortex: the $\mathrm{J} 1 /$ tenascin glycoprotein in the mouse somatosensory cortical barrel field. Dev Biol 131:243-260.

Steindler DA, O'Brien TF, Laywell E, Harrington K, Faissner A, Schachner M (1990) Boundaries during normal and abnormal brain development: in vivo and in vitro studies of glia and glycoconjugates. Exp Neurol 109:35-56.

Tessier-Lavigne M, Placzek M, Lumsden A, Dodd J, Jessell T (1988) Chemotropic guidance of developing axons in the mammalian central nervous system. Nature 336:775-778.

Vanselow J, Thanos S, Godement P, Henke-Fahle S, Bonhoeffer F (1989) Spatial arrangement of radial glia and ingrowing retinal axons in the chick optic tectum during development. Dev Brain Res 45:15-27.

Whitehead M, Morest DK (1981) Dual populations of efferent and afferent cochlear axons in the chicken. Neuroscience 6:2351-2365.

Wizenmann A, Thanos S, Boxberg YV, Bonhoeffer F (1993) Differential reaction of crossing and non-crossing axons on cell membrane preparations from the chiasm midline: an in vitro study. Development 117:725-735.

Wu D-Y, Jhaveri S, Schneider GE (1995) The changing glial environment of the Syrian hamster superior colliculus in relation to the timing of retinal axon growth and regeneration. J Comp Neurol 358:206-218.

Young MJ, Sower AC, Jhaveri S (1997) Retinal explants show decreased outgrowth on midline vs. lateral tectal glia. Soc Neurosci Abstr 23:874

Zallen JA, Yi BA, Bargmann C (1998) The conserved immunoglobulin superfamily member sax $3 /$ robo directs multiple aspects of axon guidance in C. elegans. Cell 92:217-227. 